\title{
SIMULATION OF PROPAGATIVE INSTABILITY IN SHEAR USING GRADIENT-ENHANCED AND VISCOPLASTIC MODEL ${ }^{1}$
}

\author{
Marzena Mucha*, Balbina Wcislo, Jerzy Pamin \\ Chair for Computational Engineering, Cracow University of Technology, \\ Warszawska 24, 31-155 Kraków, Poland \\ *Corresponding author: mmucha@L5.pk.edu.pl
}

\begin{abstract}
The research presented in this paper is focused on simulation of a propagative instability called Lueders bands using large strain plasticity with Huber-Mises-Hencky yield function. Two types of regularization are used: gradient-enhanced plasticity and viscoplasticity. Regularization is needed to avoid mesh sensitivity associated with the classical continuum description. A special sample is used to study Lueders band propagation in shear, its shape is motivated by experiments. The gradient-enhanced model used in computation provides a more reliable regularization than the viscoplastic model.
\end{abstract}

Key words: Lueders bands, shear, gradient plasticity, viscoplasticity

\section{INTRODUCTION}

Material or geometrical softening often leads to localized deformation that can be stationary, for instance shear band or a neck, or propagative like Lueders bands or Portevin Le Chatelier (PLC) effect. The instability classification is proposed in (Estrin \& Kubin, 1995; Sluys \& Wang, 1998). Lueders bands were tested mostly in tension, see e.g. (Sun et al., 2003), but also in bending (Kyriakides et al., 2008; Hallai \& Kyriakides, 2011a; Hallai \& Kyriakides, 2011b) and in shear (Mazière et al., 2017). Such unstable material behaviour has been a subject of extensive research because of its significance in several fields of science and engineering, including metallurgic processes, as well as the design of machines and civil engineering structures.

In this paper two large strain models are used to simulate Lueders bands which are observed for example in mild steel at room temperature, see for instance
(Hallai \& Kyriakides, 2013). Their character is usually transient, however they influence the structural performance, so their understanding is important. In order to avoid mesh sensitivity associated with the classical continuum description of softening, regularization is provided in the model by gradients (gradient-enhanced model) or viscosity (viscoplastic model). Numerical simulations are preformed using AceGen and AceFEM numerical packages for Wolfram Mathematica (Korelc, 2009).

The idealized stress-strain diagram associated with Lueders bands propagation is shown in figure 1 . At the upper yield limit softening occurs and localized stationary band is formed. Propagation starts when the lower yield stress is reached and a plastic fronts forms. During this process, the plastic strains accumulate along the sample. After reaching the Lueders strain hardening starts and the deformation can become uniform. This process is fairly easy to trace both experimentally and numerically for tensile specimens. In this paper, motivated by the work of

${ }^{1}$ The paper presented during YIC 2019, ECCOMAS Young Investigators Conference held in Kraków, Poland on September 1-6, 2019 
(Mazière et al., 2017), it is attempted to simulate the Lueders bands propagation in almost pure shear process zone, using a special sample geometry.

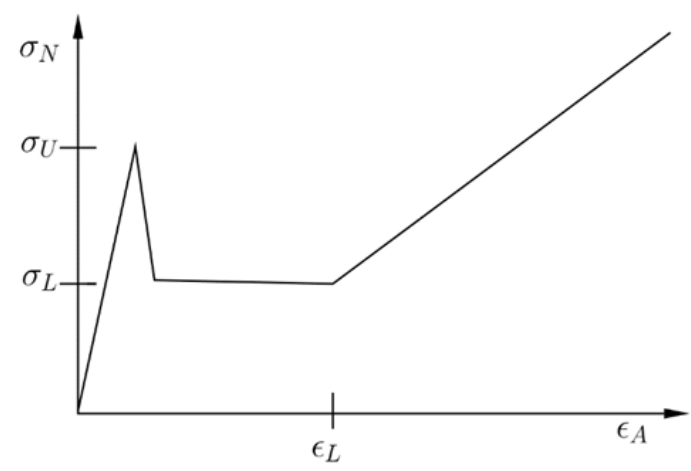

Fig. 1. Simplified nominal stress vs. averaged strain relation for specimen deformation involving Lueders effect.

The paper is divided into four sections. Section 2 contains a brief description of the gradient-enhanced and viscoplastic models. Section 3 contains the presentation of numerical results. Conclusions are summarized in Section 4

\section{BRIEF DESCRIPTION OF THE CONSTITUTIVE MODELS}

The material models used in the simulation of isothermal response are summarized in this section. They are based on large strain formulations (Simo, 1988, Wriggers et al., 1992, Geers, 2004).

A deformable continuous isotropic body is considered. Vector $\mathbf{X}$ denotes the reference location of a body particle at time $t_{0}$ and vector $\mathbf{x}$ identifies the current position of particle $\mathrm{X}$ at time t. Function $\mathbf{x}=\varphi(\mathbf{X}$, $t)$ specifies the motion of the body. The deformation gradient $\mathbf{F}$ is defined as usual:

$\mathbf{F}=\frac{\partial \varphi(\mathbf{X}, t)}{\partial \mathbf{X}}$

A decomposition of the deformation gradient into elastic and plastic parts is performed, see (Lee, 1969; Lee \& Liu, 1967):

$$
\mathbf{F}=\mathbf{F}^{e} \mathbf{F}^{p}
$$

The elastic left Cauchy-Green tensor is defined as:

$$
\mathbf{b}^{e}=\mathbf{F}^{e}\left(\mathbf{F}^{e}\right)^{\mathrm{T}}
$$

For the classical (rate and gradient-independent) theory the free energy potential per unit volume in reference configuration is decomposed additively, see (Simo, 1988; Wriggers et al., 1992):

$\psi\left(\mathbf{b}^{e}, \gamma\right)=\psi^{e}\left(\mathbf{b}^{e}\right)+\psi^{p}(\gamma)$

and the following components are assumed in the employed model:

$$
\begin{aligned}
& \psi^{e}\left(\mathbf{b}^{e}\right)=\frac{1}{2} G\left(\operatorname{tr}\left(\operatorname{det}\left(\mathbf{b}^{e}\right)^{-1 / 3} \mathbf{b}^{e}\right)-3\right)+\frac{1}{2} K \ln \left(J^{e}\right)^{2} \\
& \psi^{p}(\gamma)=\frac{1}{2} H \gamma^{2}
\end{aligned}
$$

In equation (5) $G$ and $K$ are elastic moduli, $J^{e}=$ $\operatorname{det} \mathbf{F}^{e}, H$ is linear isotropic hardening modulus and $\gamma$ is an equivalent plastic strain. The Kirchhoff stress tensor and the hardening function are derived from the free energy potential:

$$
\tau=2 \frac{\partial \psi}{\partial \mathbf{b}^{e}} \mathbf{b}^{e}, \quad h=\frac{\partial \psi}{\partial \gamma}
$$

In this paper the following yield function is in general adopted:

$F_{p}(\boldsymbol{\tau}, \gamma, \dot{\gamma}, \omega)=f(\boldsymbol{\tau})-\sigma_{y}(\gamma, \dot{\gamma}, \omega) \leq 0$

where $f(\tau)$ is the Huber-Mises-Hencky (HMH) stress measure and $\sigma_{y}$ represents multi-branch hardening described separately for the viscoplastic model (dependent on the equivalent plastic strain rate) and the gradient-enhanced model (where damage-like variable $\omega$ reduces the yield strength) in the subsections below. The following definitions are used:

$$
\begin{aligned}
& f(\tau)=\sqrt{2 J_{2}} \\
& J_{2}=\frac{1}{2} \tau_{d e v}^{2} \cdot \mathbf{I}
\end{aligned}
$$

where $\tau_{d e v}$ is the deviatoric part of stress tensor and I is identity matrix. It is noted that a model which combines the two regularization effects simultaneously is not considered in this paper, although this possibility was discussed for instance in (Oka et al., 1998; Sluys and Wang, 1998). Following (Simo, 1988), the associated flow rule is adopted for the Lie derivative of $\mathbf{b}^{e}$ :

$\frac{1}{2} \mathcal{L}_{v} \mathbf{b}^{e}=\dot{\lambda} \mathbf{N b}^{e}$

where $\mathbf{N}$ is the normal to the yield surface in the reference configuration and $\dot{\lambda}$ is the plastic multiplier satisfying the standard Kuhn-Tucker conditions:

$\dot{\lambda} \geq 0, \quad F_{p} \leq 0, \quad \dot{\lambda} F_{p}=0$ 
The conditions are also satisfied for the regularized models. Moreover, the plastic multiplier plays the role of the plastic strain measure $\dot{\gamma}=\dot{\lambda}$. It is mentioned that due to large deformations geometrical softening is present in the description, see (Okazawa, 2009).

\subsection{Gradient-enhanced model}

The yield function for the gradient-enhanced model is defined according to (Geers, 2004):

$F_{p}(\boldsymbol{\tau}, \gamma, \omega)=f(\boldsymbol{\tau})-\sigma_{y}(\gamma, \omega) \leq 0$

where the yield strength depends on a degradation parameter $\omega$ in the following way (see figure 2a):

$\sigma_{y}(\gamma, \omega)= \begin{cases}\sigma_{y 0}(1-\omega) & \gamma \leq \gamma_{1} \\ {\left[\sigma_{y 0}+H_{2}\left(\gamma-\gamma_{1}\right)\right]\left(1-\omega_{1}\right)} & \gamma>\gamma_{1}\end{cases}$

where $H_{2} \geq 0$ and softening is induced by the plastic degradation variable $\omega \in[0,1]$. Its evolution is described by the following function:

$\omega=1-\exp (-\beta z)$

where $\beta$ is a ductility parameter and $z$ is a non-local variable obtained from the following averaging equation (Peerlings et al., 1996):

$z-l^{2} \nabla_{0}^{2} z=\kappa$

in which $l$ is an internal length scale, $\nabla_{0}$ is the gradient operator in material description and $\kappa$ is a history variable $\kappa=\sqrt{2 / 3} \gamma$.

Homogeneous natural boundary conditions are assumed for the averaging equation. It is mentioned that in the numerical solution algorithm the averaged plastic strain $z$ is discretized in addition to displacements and two-field finite elements are used. It is moreover stressed that the yield strength degradation is frozen $\omega=\omega_{1}$ when $\gamma=\gamma_{1}$ to exclude material softening in the second hardening stage.

\subsection{Viscoplastic model}

The viscoplastic model is based on the consistency concept, cf. (Wang, 1997). In the model, in contrast to the classical Perzyna and Duvaunt-Lions approaches, the plastic consistency equation is dependent on an equivalent viscoplastic strain rate, see (Wang et al., 1997; Winnicki et al., 2001). The yield function is rate-dependent:

$F_{p}(\tau, \gamma, \dot{\gamma})=f(\tau)-\sigma_{y}(\gamma, \dot{\gamma}) \leq 0$ and the yield strength is:

$\sigma_{y}(\gamma, \dot{\gamma})=\sqrt{2 / 3}\left(\sigma_{y 0}+h(\gamma)\right)+\xi \dot{\gamma}$

where $\xi$ is viscosity, and the following hardening function is employed:

$h(\gamma)= \begin{cases}H_{1} \gamma & \gamma \leq \gamma_{1} \\ H_{1} \gamma_{1}+H_{2}\left(\gamma-\gamma_{1}\right) & \gamma>\gamma_{1}\end{cases}$

with $H_{1}<0$ and $H_{2}>0$.

a)

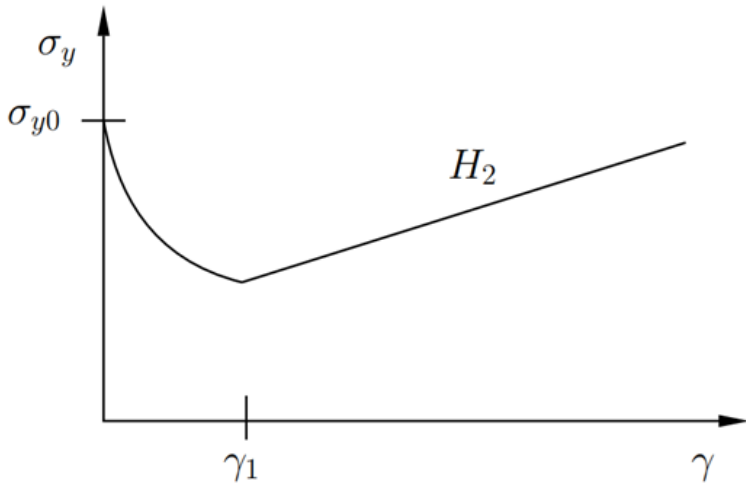

b)

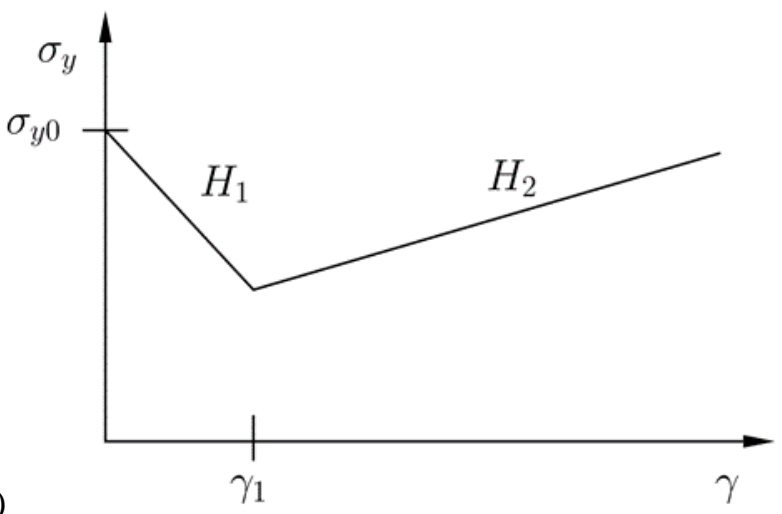

Fig. 2. Yield stress vs equivalent plastic strain relations used in gradient (a) and viscoplastic (b) models.

Figure $2 \mathrm{~b}$ shows the simplified multilinear model of yield strength evolution with the increase of the plastic strain measure $\sigma_{y}(\gamma)$ used in this paper.

\section{SIMULATION RESULTS}

A special sample geometry is used to simulate Lueders bands in shear, see figure 3 . When the sample is stretched, owing to its shape, which is motivated by the experiments, in the middle zone almost pure shear is obtained. Since the Lueders bands can be observed only for this central part (process zone marked by a box in figure 3 on the right), simulation results are presented only for this part. The dimensions of the shear sample are height $150 \mathrm{~mm}$, width $40 \mathrm{~mm}$, thickness $1 \mathrm{~mm}$. In the middle of the strip the thickness is 
reduced to $0.5 \mathrm{~mm}$ (marked by an inner box in figure 3 right). Vertical displacement is restrained at the bottom of the sample and imposed at the top (displacement rate is $0.2 \mathrm{~mm} / \mathrm{s}$ ). Zero horizontal displacement is assumed along the symmetry axis of the middle strip to avoid spurious rotation. Out of plane displacement is blocked only at one point (plane stress conditions). Eight-node cubic elements with linear shape functions are used (for the gradient model similar shape function are used for both interpolated fields). F-bar enhancement is employed to avoid volumetric locking, see (de Souza Neto et al., 2008). The total number of elements are 78384. The material model parameters are shown in table 1 .

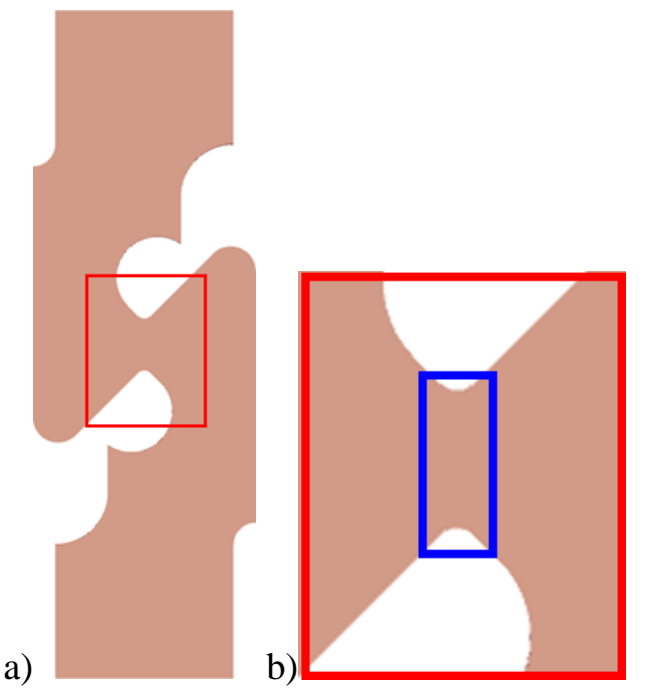

Fig. 3. Specimen geometries.

Table 1. Material parameters.

\begin{tabular}{|c|c|c|c|}
\hline Property & Symbol & Value & Unit \\
\hline Young Modulus & $E$ & $207 \times 10^{9}$ & $\mathrm{~N} / \mathrm{m}^{2}$ \\
\hline Poisson ratio & $v$ & 0.29 & - \\
\hline $\begin{array}{c}\text { Yield threshold } \\
\text { in tension }\end{array}$ & $\sigma_{y 0}$ & $450 \times 10^{6}$ & $\mathrm{~N} / \mathrm{m}^{2}$ \\
\hline $\begin{array}{c}\text { Linear harde- } \\
\text { ning modulus }\end{array}$ & $H_{1}$ & $-0.005 E$ & $\mathrm{~N} / \mathrm{m}^{2}$ \\
\hline $\begin{array}{c}\text { Linear harde- } \\
\text { ning modulus }\end{array}$ & $H_{2}$ & $0.005 E$ & $\mathrm{~N} / \mathrm{m}^{2}$ \\
\hline First threshold & $\gamma_{1}$ & 0.15 & $\mathrm{~mm}$ \\
\hline $\begin{array}{c}\text { Enforced displa- } \\
\text { cement }\end{array}$ & $\Delta L$ & 5 & $\mathrm{MPa} \mathrm{s}$ \\
\hline Viscosity & $\xi$ & $0 / 10 / 100 / 200$ & $\mathrm{~s}$ \\
\hline$t_{\max }$ & $t_{\max }$ & 25 & - \\
\hline Ductility & $\beta$ & 1 & $\mathrm{~mm}$ \\
\hline Internal length & $l$ & $5 / 10 / 20$ & \\
\hline
\end{tabular}

In figure 4 the diagrams of total force $(\Sigma R)$ versus imposed displacement multiplier $\lambda$ for the two models are shown. Two aspects are investigated respectively: dependence on internal length or viscosity. It can be observed that the influence of the internal length is small and the diagrams are smooth, see figure 4 (top). Viscosity affects the results more visibly. For a smaller value of viscosity, the diagrams during the softening stage are steeper and strong oscillations can be seen when the band travels through the sample. If the value of viscosity increases, the oscillations are smoothed, see figure 4 (bottom). It is mentioned that oscillations are observed in experiments, $\mathrm{cf}$ (Mazière et al., 2017), but here they are related to numerical effects and hence undesirable. For the gradient-enhanced model differences between the diagrams can be seen in the last stage of stretching contrary to the viscoplastic model where the diagrams differ significantly in the initial stage. The differences for the gradient-enhanced model in the final stage are caused by stronger localization for lower values of the internal length. Due to the very small process zone for the shear sample, softening stage is very short and cannot be seen in the diagrams. The final load values obtained for the two models differ because of the difference in softening representation and regularization.
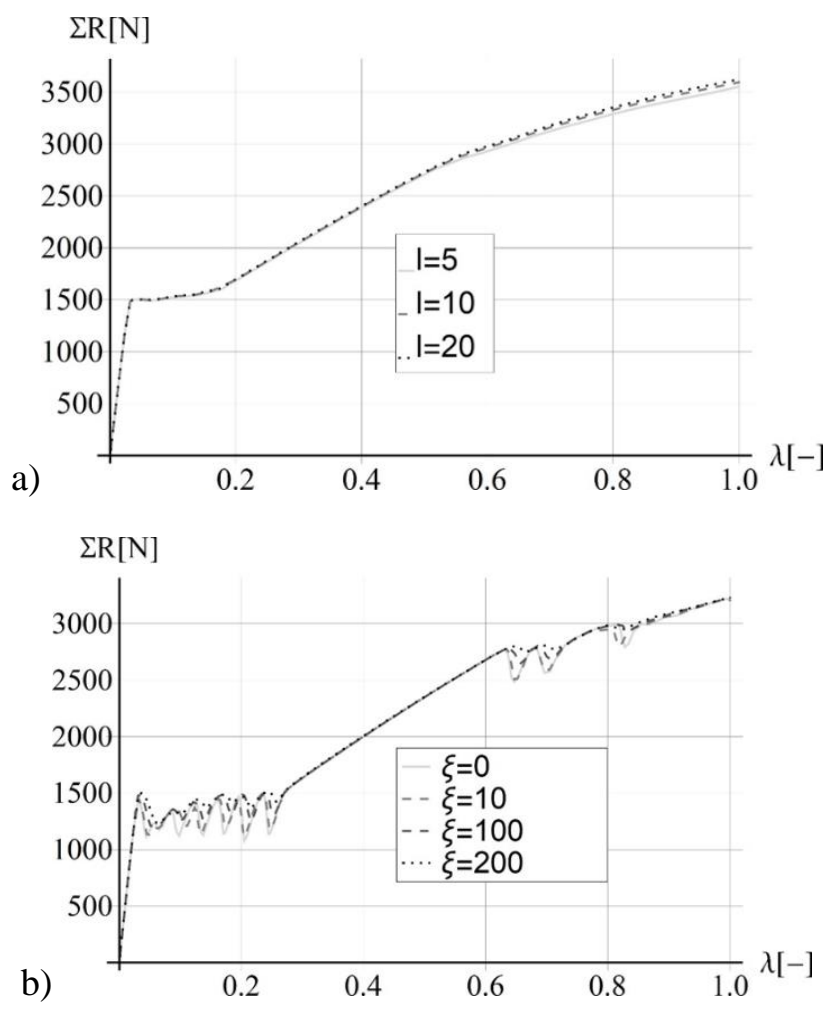

Fig. 4. Sum of reactions vs displacement multiplier for different internal lengths ( $a$ - gradient model) and different viscosities ( $b$ - viscoplastic model).

In figure 5 the distributions of $(\Delta \dot{\gamma} / \Delta t$, first set) and $\gamma$ (second set) are given. The plots of $\dot{\gamma}$ and $\gamma$ along the horizontal axis in the middle of the sample are additionally presented below the plastic strain (rate) profiles. First a band is formed in the middle of 
the process zone (see figure 5 left), then two plastic fronts form and start to propagate in opposite directions (see figure 5, middle) and finally hardening dominates when the plastic state is active in the whole process zone (see figure 5 right). This is interpreted as Lueders type plastic process evolution. Please notice that the plastic strains are out of the zone with reduced thickness. In the work of (Mazière et al., 2017) the plastic fronts initially form at two sides of the shear strip and propagate towards the center, while in our experiment opposite situation is simulated. This is probably caused by the geometry of the process zone with weakest cross section along the antysimmetry axis.

The viscoplastic model gives similar results to the gradient enhanced model provided that the value of viscosity is high, see figure 6 , but for the gradient- enhanced model the results are almost symmetric. To compare the results see the middle plots in figures 5 and 6 . For the viscoplastic model the diagrams are shifted to the right. This difference can be observed in particular for the viscoplastic model where a local strain concentration can be observed in the top right part of the process zone. The differences in the behavior can be caused by oscillations observed for the model with viscosity.

Lueders bands propagation in shear is different than the propagation in tension, see for example the results for tension tests in (Sun et al., 2003). The shape of tension sample enables the Lueders front propagation through almost whole sample while for the shear sample the process zone is relatively narrow.

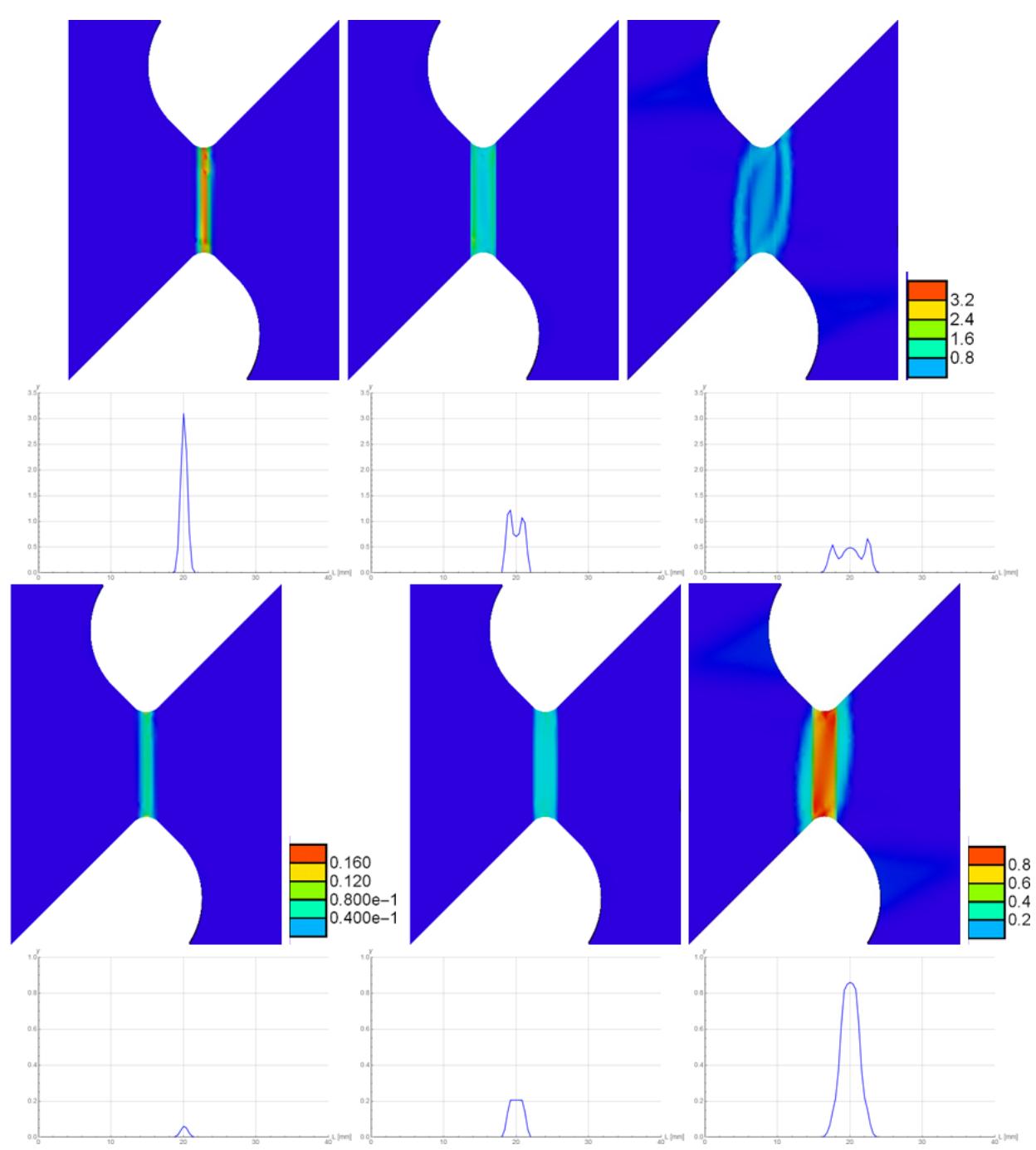

Fig. 5. Distribution of $\dot{\gamma}$ (first set) and distribution of $\gamma$ (second set) with corresponding diagrams plotted along horizontal cross section in the middle of the zone for internal length equal to $10 \mathrm{~mm}$ (gradient-enhanced model). From left $\lambda=0.05, \lambda=0.20, \lambda=1$ 


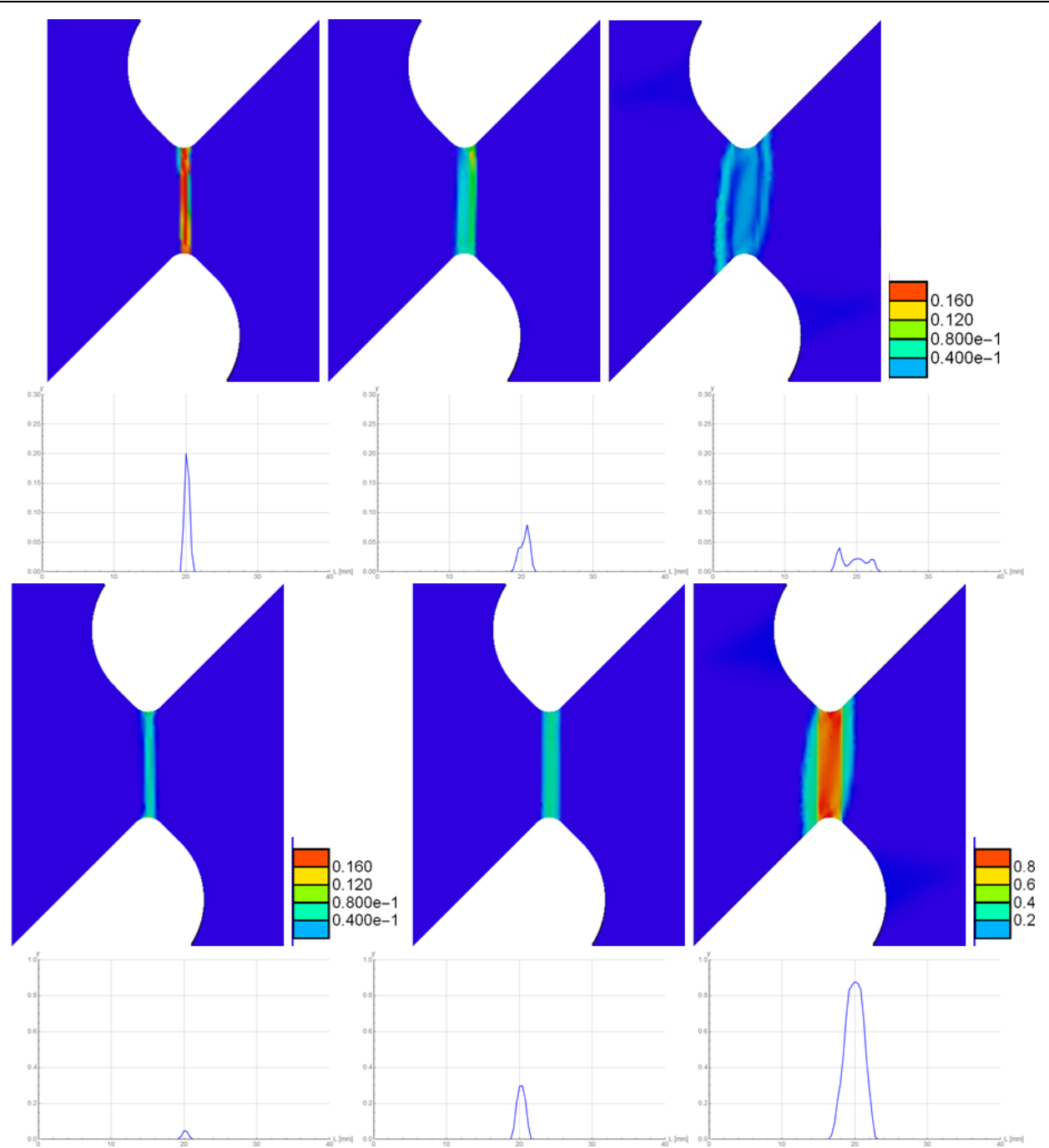

Fig. 6. Distribution of $\dot{\gamma}$ (first set) and distribution of $\gamma$ (second set) with corresponding diagrams plotted along horizontal cross section in the middle of the zone for viscosity equal to 100. From left $\lambda=0.04, \lambda=0.16, \lambda=1$.

\section{CONCLUSIONS}

Two large strain plasticity models, gradient-enhanced and viscoplastic, both with Huber-MisesHencky yield function, have been used to simulate Lueders bands propagation in shear. In the considered cases the gradient model seems to provide better regularization than the viscoplastic model. If the value of viscosity is too low, strong oscillations occur in the load-displacement diagram. To validate the presented regularized constitutive models experiments on metallic samples are now planned.

\section{ACKNOWLEDGMENTS}

The authors acknowledge valuable discussions on the research with Prof. T. Jankowiak from Poznań University of Technology (PUT). Part of the research was supported by the National Science Centre of Poland within grant number 2018/31/N/ST8/03573.

\section{REFERENCES}

de Souza Neto, E., Peric, D., Owen, D., 2008, Computational methods for plasticity. Theory and applications. John Wiley $\&$ Sons, Chichester.

Estrin, Y., Kubin, L., 1995, Spatial coupling and propagative plastic instabilities. In Mühlhaus, H.-B., editor, Continuum Models for Materials with Microstructure, John Wiley \& Sons, Chichester, 395-450.

Geers, M.G.D., 2004, Finite strain logarithmic hyperelasto-plasticity with softening: a strongly non-local implicit gradient framework, Comput. Methods Appl. Mech. Engrg., 193, 3377-3401.

Hallai, J., Kyriakides, S., 2011a, On the effect of Lüders bands on the bending of steel tubes. Part I: Experiments, Int. J. Solids Struct., 48, 3275-3284.

Hallai, J., Kyriakides, S., 2011b, On the effect of Lüders bands on the bending of steel tubes. Part II: Analysis, Int. J. Solids Struct., 48, 3285-3298.

Hallai, J., Kyriakides, S., 2013, Underlying material response for Lüders- like instabilities, Int. J. Plasticity, 47, 1-12.

Korelc, J., 2009, Automation of primal and sensitivity analysis of transient coupled problems, Computational Mechanics, 44, 631-649. 
Kyriakides, S., Ok, A., Corona, E., 2008, Localization and propagation of curvature under pure bending in steel tubes with Lüders bands, Int. J. Solids Struct., 45(10), 3074-3087.

Lee, E.H., 1969, Elastic plastic deformation at finite strain, ASME Trans. J. Appl. Mech., 36, 1-6.

Lee, E.H., Liu, D.T., 1967, Finite-strain elastic-plastic theory with application to plane-wave analysis, J. Appl. Phys., 38 19-27.

Mazière, M., Luis, C., Marais, A., Forest, S., Gaspèrini, M., 2017, Experimental and numerical analysis of the Lüders phenomenon in simple shear, Int. J. Solids Struct., 106-107, 305314.

Oka, F., Mühlhaus, H.-B., Yashima, A., Sawada, K., 1998, Quasistatic and dynamic characteristics of strain gradient dependent non-local constitutive models, In: de Borst, R., van der Giessen, E., editors, Material Instabilities in Solids, IUTAM, John Wiley \& Sons, Chichester, 387-404.

Okazawa, S., 2009,. Structural bifurcation for ductile necking localization, Int. J. Nonlinear Mech., 45, 35-41.

Peerlings, R.H.J., de Borst, R., Brekelmans, W.A.M., de Vree, J.H.P, 1996, Gradient-enhanced damage for quasi-brittle materials, Int. J. Numer. Meth. Engng, 39, 3391-3403.

Simo, J.C., 1988, A framework for finite strain elastoplasticity based on maximum plastic dissipation and the multiplicative decomposition: Part 1. Continuum formulation, Comput. Methods Appl. Mech. Engrg, 66, 199-219.

Sluys, L.J., Wang, W.-M., 1998, Macroscopic modelling of stationary and propagative instabilities, In: de Borst, R., van der Giessen, E., editors, Material Instabilities in Solids, IUTAM, John Wiley \& Sons, Chichester, 489-505.

Sun, H.B., Yoshida, F., Ma, X., Kamei, T., Ohmori, M., 2003, Finite element simulation on the propagation of Lüders band and effect of stress concentration, Materials Letters, 57(21), 3206-3210.

Wang, W.M., 1997, Stationary and propagative instabilities in metals - a computational point of view, Ph.D. dissertation, Delft University of Technology, Delft.

Wang, W.M., Sluys, L.J., de Borst, R., 1997, Viscoplasticity for instabilities due to strain softening and strain-rate softening, Int. J. Numer. Meth. Engng, 40(20), 3839-3864.

Winnicki, A., Pearce, C.J., Bićanić, N., 2001, Viscoplastic Hoffman consistency model for concrete, Comput. \& Struct., 79, 7-19.

Wriggers, P., Miehe, C., Kleiber, M., Simo, J., 1992, On the coupled thermomechnical treatment of necking problems via finite element methods, Int. J. Numer. Meth. Engng, 33, 869883.

\section{SYMULACJE PROPAGUJACEJ SIE NIESTATECZNOŚCI MODELAMI GRADIENTOWEJ PLASTYCZNOŚCI I LEPKOPLASTYCZNOŚCI.}

\section{Streszczenie}

W artykule zaprezentowano symulacje numeryczne propagujących się pasm lokalizacji odkształcenia nazywanych pasmami Luedersa wykorzystując model dużych deformacji z funkcją plastyczności Hubera-Mises-Hencky'ego. Użyto dwóch typów regularyzacji, gradientowej plastyczności oraz lepkoplastyczności. Regularyzacja jest niezbędna celem uniknięcia zależności wyni- ków od gęstości siatki elementów skończonych. Do przeprowadzania obliczeń w warunkach czystego ścinania została użyta specjalna próbka, której kształt motywowany jest eksperymentami. Model gradientowy wykazał lepsze możliwości regularyzacyjne niż model lepkoplastyczny.

Received: August 27, 2019. Received in a revised form: October 31, 2019. Accepted: November 15, 2019. 